\title{
Effect of Moxonidine on Putative Sympathetic Neurons in the Rostral Ventrolateral Medulla of the Rat
}

\author{
Antonio R. Granata \\ Department of Psychiatry and Physiology, New York Medical College, Valhalla, N.Y., USA
}

\section{Key Words}

Rostral ventrolateral medulla - Antihypertensive drugs . Intracellular recording - Sympathetic premotor neurons . Imidazoline receptors $\cdot \alpha_{2}$-Adrenergic receptors by imidazoline-derivative adrenergic agonists. These results could help to understand the hypotensive effects of moxonidine.

Copyright $@ 2004$ S. Karger AG, Basel

\begin{abstract}
We used an intracellular recording technique in vitro to investigate the effects of moxonidine on neurons in the rostral ventrolateral medulla (RVLM) with electrophysiological properties similar to premotor sympathetic neurons in vivo. These neurons were classified as firing regularly and irregularly, according to previous reports. Moxonidine is a sympathoinhibitory and antihypertensive agent that is thought to be a ligand of $\alpha_{2}$-adrenergic receptors and imidazoline type- 1 receptors in the RVLM. Moxonidine (2-10 $\mu \mathrm{M})$ was applied to the perfusate on 4 irregularly firing neurons, and 2 regularly firing neurons. Moxonidine $(2 \mu M)$ produced only minor depolarization in 2 of these neurons. However, on 4 tested neurons, moxonidine $(10 \mu M)$ elicited a profound inhibitory effect with hyperpolarization (near $-20 \mathrm{mV}$ ); these neurons practically ceased firing. These changes were partially reversible. The results would indicate that neurons in the RVLM, recorded in vitro and with similar electrophysiological characteristics to a group of neurons previously identified in vivo in the same bulbar region as barosensitive premotor sympathetic neurons, can be modulated
\end{abstract}

\section{KARGER}

Fax +41613061234

E-Mail karger@karger.ch

www.karger.com
(C) 2004 S. Karger AG, Basel

1424-862X/04/0135-0241\$21.00/0

Accessible online at:

www. karger.com/nsg

\section{Introduction}

The rostral ventrolateral medulla (RVLM) is critically involved in the central control of cardiovascular sympathetic activity; additionally, bulbospinal neurons in this area establish the level of excitability of sympathetic preganglionic neurons in the intermediolateral column and in the lamina $X$ of the spinal cord. The spontaneous firing pattern of cardiovascular sympathetic premotor neurons in the RVLM, studied with intracellular recording techniques in vivo [1,2], is similar to that of isolated sympathetic vasomotor efferent fibers related to the cardiac cycle [3]. Overall, these groups of medullospinal neurons in the RVLM are accepted as the vasomotor efferent projection of the medulla, and perform as premotor sympathetic vasomotor neurons.

There is experimental evidence supporting the existence of at least two different types of barosensitive premotor sympathetic RVLM neurons with projections to the spinal cord. First, a group of neurons fire spontaneous action potentials with a very regular pattern in vitro [4-6] and in vivo during pronounced hypotension [1], and
Antonio R. Granata, MD, PhD

New York Medical College

Basic Science Building, Room 415

Valhalla, NY 10595 (USA)

Tel. +1 914594 3538, Fax +1 718430 8819, E-Mail RAFA220@yahoo.com 
receive inhibitory postsynaptic potentials synchronized to the cardiac cycle during normal arterial blood pressure [1, 2]. Second, a different group of neurons fire in an irregular mode and receive excitatory postsynaptic potentials locked to the cardiac cycle. These neurons are hyperpolarized by systemic increases in blood pressure or aortic nerve stimulation $[1,2]$.

It is well known that adrenergic mechanisms are involved in the central control of cardiovascular function [7]. Moreover, the RVLM is the site of action of different pharmacological agents that affect catecholaminergic transmission [8], and are used to treat human vascular hypertension; for example the $\alpha_{2}$-adrenergic agonist clonidine $[9,10]$. Accordingly, pharmacological studies have demonstrated that intraparenchymal injections of adrenergic agonists into the RVLM in vivo activate different subtypes of $\alpha$-adrenergic receptors and probably $\beta$-adrenergic receptors, eliciting either a decrease or an increase in arterial blood pressure and sympathetic nerve activity, respectively $[11,12]$.

Moreover, different adrenergic agonists applied in vitro to a medullary slice preparation containing the RVLM produced substantial changes in electrophysiological parameters on putative sympathetic neurons [13-15]. Hence, bulbospinal barosensitive neurons in the RVLM are thought to be the sites of action of adrenergic agents mediating central sympathoinhibitory responses [for review, see 16]. For this reason, different investigators have studied the effect of adrenergic agents upon premotor sympathetic neurons in the RVLM in vivo, and on putative RVLM sympathetic neurons in vitro $[13,17,18]$.

The pharmacological mechanism involved in the sympathoinhibitory effect in the RVLM of adrenergic agonists with an imidazoline molecular structure is still a matter of discussion. Some investigators support the idea that these drugs inhibit central sympathetic activity by activating $\alpha_{2}$-adrenergic receptors [19]. On the other hand, for some imidazoline-related drugs, like moxonidine, that are effective for treating different forms of the hypertensive syndrome [10,20,21], it was proposed that they mediate their central sympatholytic effect by activating imidazoline receptors in the RVLM $[22,23]$, and therefore reduce central sympathetic tonic activity [10, 24]. However, the mechanism of action and in particular the type(s) of neurons in the RVLM targeted by this drug are still unclear.

The aim of this study is to investigate in vitro the effect of moxonidine on RVLM neurons with similar electrophysiological properties to those neurons in the RVLM characterized in vivo as barosensitive and sympathoexcit- atory $[1,2]$. The characterization of sympathoexcitatory neurons in slice preparations is difficult because of the absence of barosensory inputs and the impracticality of correlating the neuronal activity of these neurons with the sympathetic outflow. Nevertheless, as explained in previous publications $[13,25]$, we characterized putative sympathoexcitatory neurons according to electrophysiological properties similar to those recorded and characterized in vivo as sympathetic premotor neurons in the RVLM. For this purpose, we recorded intracellularly in vitro from neurons located in a coronal medullary slice preparation that included the RVLM.

\section{Methods}

The experiments were done on male Sprague-Dawley rats (90$120 \mathrm{~g}$ ) anesthetized with ether and decapitated. The brain was rapidly removed from the skull and placed in a dish containing Ringer solution $\left(4{ }^{\circ} \mathrm{C}\right)$ equilibrated with $95 \% \mathrm{O}_{2}$ and $5 \% \mathrm{CO}_{2}$. The composition of the Ringer solution was $(\mathrm{mM}): 124 \mathrm{NaCl} ; 5.0 \mathrm{KCl} ; 1.3$ $\mathrm{MgSO}_{4} ; 1.25 \mathrm{KH}_{2} \mathrm{PO}_{4} ; 2.0 \mathrm{CaCl}_{2} ; 26 \mathrm{NaHCO}_{3}$, and $10.0 \mathrm{D}$-glucose. The medulla with the caudal part of the pons was dissected and fixed with cyanoacrylic glue in a frontal plane to the cutting chamber of a vibratome (Oxford Instruments). The chamber was filled with cold $\left(4^{\circ} \mathrm{C}\right)$ oxygenated Ringer solution. The medulla was cut into 400 - to 500- $\mu \mathrm{m}$ coronal slices containing the RVLM. After that, the slice sections were transferred to an incubation chamber (Medical Systems Co.) and kept in oxygenated Ringer solution at $25-27^{\circ} \mathrm{C}$ for about $1 \mathrm{~h}$. Thereafter, one slice was transferred to a recording chamber (Medical Systems Co.), in which the bottom surface of the slice was placed on filter paper held in place upon the fine nylon mesh of the chamber which was continuously superfused with oxygenated Ringer solution at a rate of $0.3-1.0 \mathrm{ml} / \mathrm{min}$ at $34 \pm 1{ }^{\circ} \mathrm{C}$.

Intracellular recordings were obtained with microelectrodes made from borosilicate filamented glass capillary tubing $(2.0 \mathrm{~mm}$ OD), and filled with a solution of 4-6\% biocytin (Sigma) in $0.05 \mathrm{M}$ of $\mathrm{KCl}$ or K-acetate $(\mathrm{pH} 7.0-7.6)$. Electrode resistances were 110$200 \mathrm{M} \Omega$. Intracellular potentials were recorded in a conventional method described in a previous publication [25] from neurons located between the rostral pole of the RVLM and a plane $500 \mu \mathrm{m}$ caudally.

\section{Current Application}

During the recording of the continuous data, there were discontinuous applications of trains (repetition rate $0.5-1.0 \mathrm{~Hz}$ ) of depolarizing or hyperpolarizing current pulses (380 ms pulse duration) with different intensity levels. The neuronal membrane input resistance was calculated from the magnitude of intracellular hyperpolarizing and depolarizing current pulses, and the corresponding changes in membrane potentials which produced the current/voltage relationship.

\section{Identification of the Recorded Neurons}

Some of the recorded neurons were intracellularly labelled with biocytin $(\mathrm{n}=6)$ by injecting 4-8 nA negative rectangular pulses of $150 \mathrm{~ms}$ duration at $3.3 \mathrm{~Hz}$ for $6-10 \mathrm{~min}$. The slice containing the 
recorded and injected neuron(s) was transferred to a fixative solution of $4 \%$ paraformaldehyde and $1.5 \%$ picric acid in phosphate-buffered saline at $\mathrm{pH} 7.4$, and stored at $4{ }^{\circ} \mathrm{C}$ overnight. After that, the slice was moved to a solution of $30 \%$ sucrose in $0.15 \mathrm{M}$ phosphate-buffered saline for $4 \mathrm{~h}$, and then sectioned on a freezing microtome into 50$\mu \mathrm{m}$-thick sections which were next rinsed several times in $0.1 \mathrm{M}$ phosphate buffer ( $\mathrm{pH}$ 7.4) and treated for histofluorescence in the intracellularly labelled neuron(s). Histological sections were incubated for $4 \mathrm{~h}$ in avidin-Texas Red 1:200 in phosphate buffer solution plus $0.1 \%$ Triton $\mathrm{X}-100$ and $1 \%$ sodium azide. At the end of the incubation period, the tissue was rinsed several times in a fresh solution of phosphate buffer for $1 \mathrm{~h}$ and the sections were mounted in a solution of glycerol in phosphate buffer (1:3) plus 1\% n-propylgallate. Sections were studied under an epifluorescence microscope with a filter combination for rhodamine (G-2A). The position of a filled neuron was determined and marked on a page from a histological atlas [26].

\section{Drug Administration}

Moxonidine $(2-10 \mu M)$ was dissolved in Ringer solution which was applied by a gravity perfusion system.

\section{Results}

Fifteen neurons lying within the RVLM from 4 rats were recorded intracellularly. These neurons had resting membrane potentials that varied from -49 to $-82 \mathrm{mV}$, and they were able to generate action potentials with amplitudes larger than $55 \mathrm{mV}$. The membrane input resistance determined by intracellular current injections ranged from 73 to $150 \mathrm{M} \Omega$.

The recorded neurons were classified as firing regularly and irregularly according to the properties explained in detail in previous publications [13, 25], and similar to those sympathetic premotor neurons characterized in vivo as firing regularly and irregularly [1], and regular and irregular sympathetic premotor neurons reported by Oshima et al. [5]. Accordingly, these neurons were divided into a group of 6 neurons firing in a regular mode (R-type), and another group of 9 neurons firing in an irregular mode (I-type). The recorded neurons were localized in the RVLM, either by intracellular injection of biocytin and searching for the avidin-Texas Red reaction, or by visual recognition of the recording site under microscope.

We tested the effect of moxonidine $(2-10 \mu M)$ applied to the perfusate while recording intracellularly from 6 neurons located in the RVLM, 2 of them classified as Rtype, and 4 as I-type.

In 2 neurons, 1 of them characterized as R-type and the other as I-type, moxonidine $(2 \mu M)$ produced very minor changes in neuronal activity. The result of one experiment done in a I-type neuron (control recordings in fig. 1A1,
A2) shows that $6 \mathrm{~min}$ after application of the drug the neuron was slightly depolarized, and the frequency of discharge increased from 11 to $18 \mathrm{~Hz}$ (fig. 1B). These minor changes were still present after $15 \mathrm{~min}$ of drug perfusion (fig. 1C). The level of depolarization in these neurons was 5-8 $\mathrm{mV}$. These changes were reversible after washing the drug out, as shown in figure $1 \mathrm{D} 1$ and D2. No change in the action potential duration or shape was noted after exposing these neurons to this concentration of moxonidine.

On the other hand, a higher concentration of moxonidine $(10 \mu M)$ elicited very appreciable changes in the neuronal activity of 3 I-type neurons and 1 R-type neuron. As shown in figure 2B, 4 min after application of the drug to the perfusate, (1) a depolarizing effect on membrane potential and (2) a 10-15\% increase in membrane input resistance were seen, and (3) the pattern of discharge became very irregular with periods of bursting. However, 24 min after perfusion of the drug (fig. 2C), the membrane potential suffered a dramatic change consisting of marked hyperpolarization ( -15 to $-20 \mathrm{mV}$ from control). In addition, the input membrane resistance remained increased and the neuron practically ceased firing. These changes were partially reversible; 16 min after washout with normal Ringer solution the membrane potential started to recover, and the neuron was firing in a very irregular pattern. However, the action potential amplitude and shape did not recover during the time period of continued intracellular recording ( $>20 \mathrm{~min}$ ), denoting some extra effect of the drug which is difficult to determine at this point.

\section{Discussion}

Imidazoline derivatives, like clonidine and moxonidine, are used to treat different types of hypertension [20]. It is accepted that moxonidine is a centrally acting drug and the main site of action is the RVLM [16]. Injections of moxonidine into the RVLM reduce blood pressure and heart rate, and this effect is blocked by the imidazoline type-1 receptor-blocker efaroxan [20]. However, little is known about the identity of the RVLM neuron(s) involved in the antihypertensive and sympathoinhibitory effect of drugs like moxonidine. It is still controversial whether $\alpha_{2}$-adrenergic receptors are also activated by moxonidine, or a combination of both imidazoline type-1 and $\alpha_{2}$-adrenergic receptors could mediate the actions of moxonidine in the RVLM [23].

The present results demonstrate an inhibitory hyperpolarizing effect of moxonidine at concentrations of $10 \mu M$ on RVLM neurons with electrophysiological prop- 


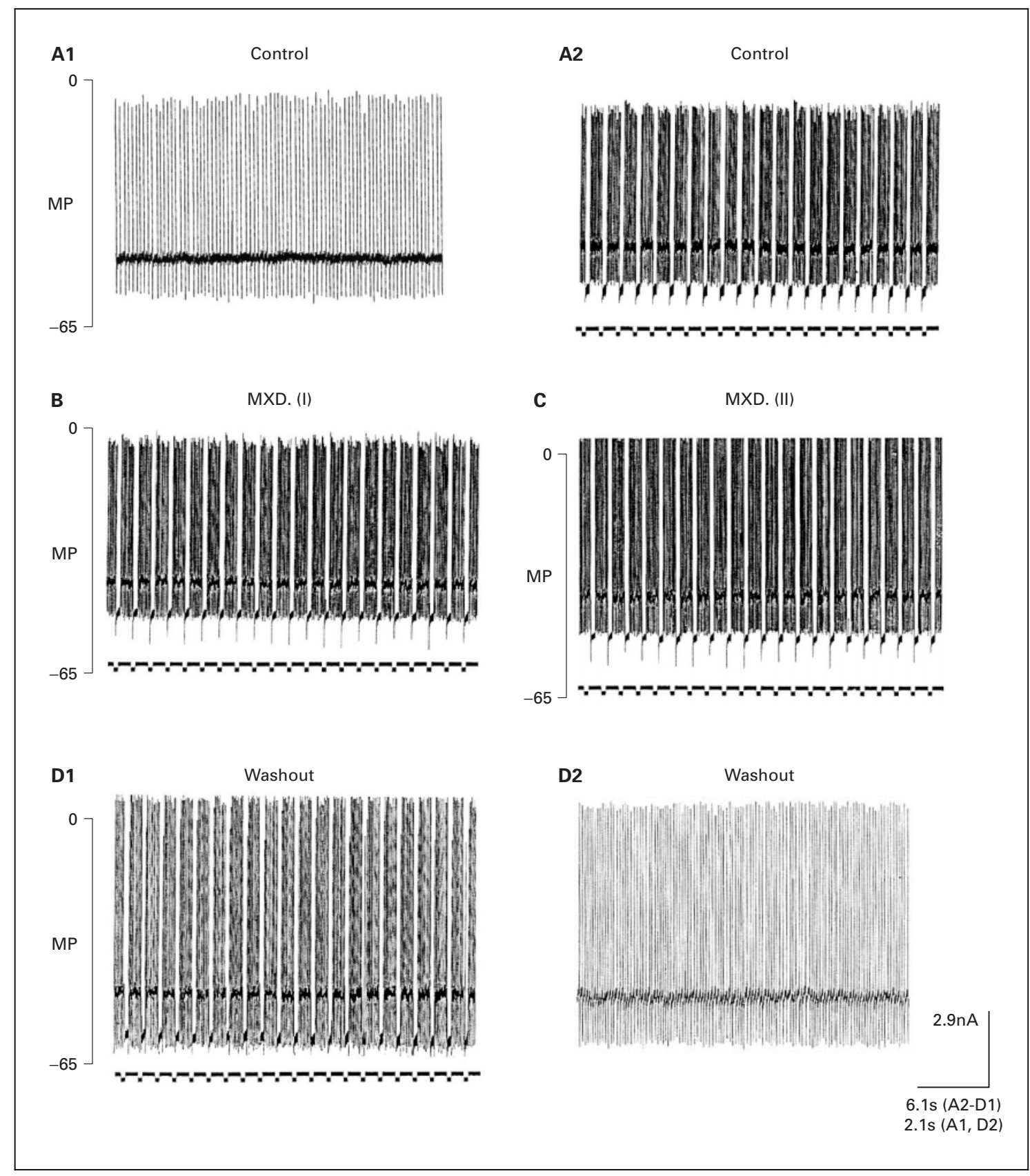

Fig. 1. Intracellular recording of an irregularly firing RVLM neuron from an in vitro slice preparation. The records show the time course of effects of the imidazoline-derivative moxonidine $(2 \mu M)$ perfusion on this neuron. A2, D1 The upper trace is the membrane potential recording which shows the deflections produced by pulses of hyperpolarizing current, and the lower trace shows the magnitude of the injection current. A1, D2 The neuron was not injected with current. A1, A2 Control: recording before moxonidine (MXD) perfusion.
B MXD (I): recording starts 6 min after perfusion onset. The membrane potential became slightly more depolarized. C MXD (II): recording starts $15.6 \mathrm{~min}$ after perfusion onset. The membrane potential remained slightly more depolarized, and the firing rate was somewhat increased. D1-D2 Washout: recording starts 11 min after washout of moxonidine. The membrane potential was hyperpolarized. However, the firing rate was decreased, but it did not recover to control levels. D2 started 2 min after the end of D1. 


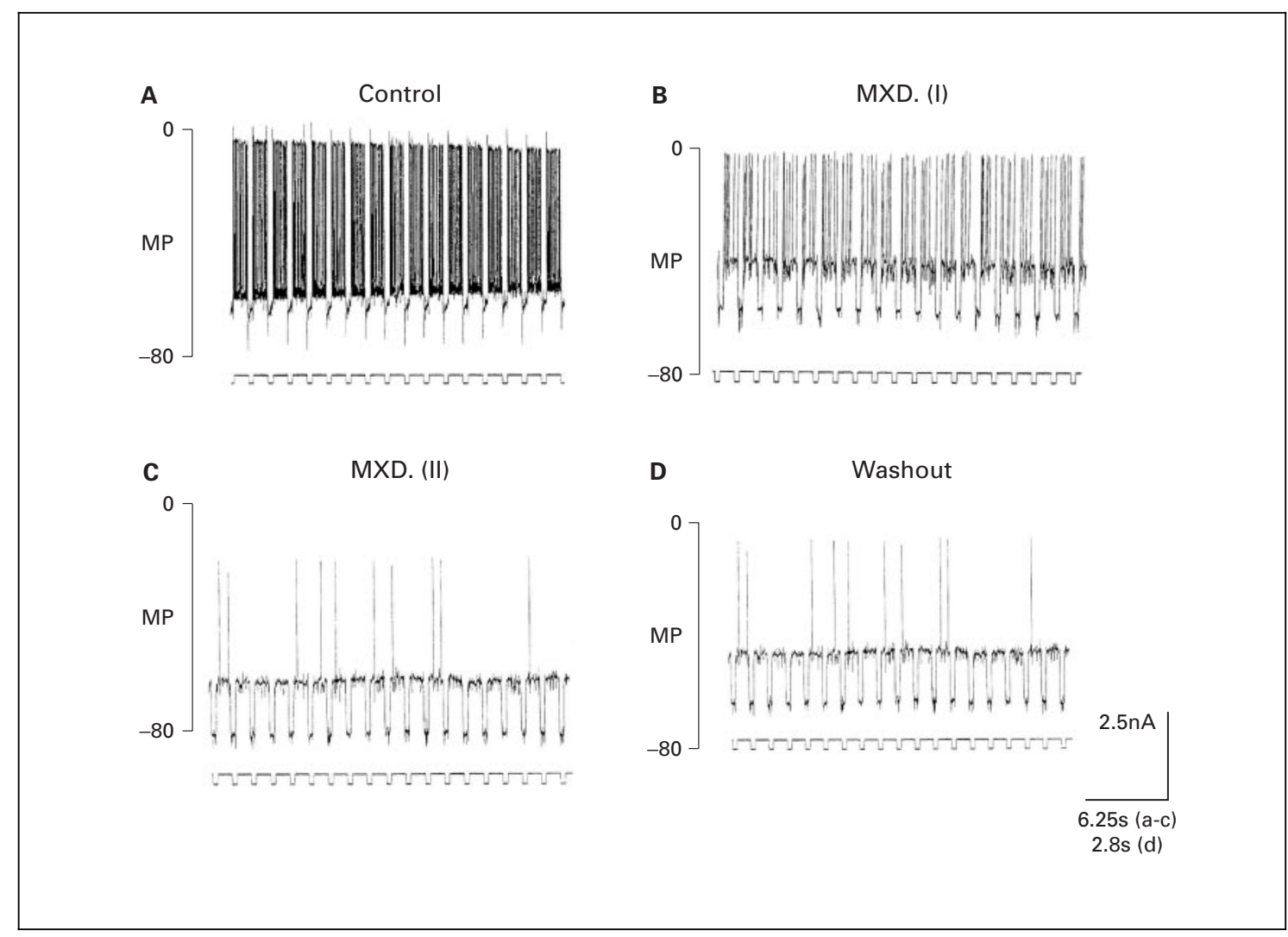

Fig. 2. Intracellular recording of another irregularly firing RVLM neuron from an in vitro slice preparation. The records show the time course of effects of moxonidine $(10 \mu M)$ perfusion on this neuron. The upper trace is the membrane potential recording which shows the deflections produced by pulses of hyperpolarizing current, and the lower trace shows the magnitude of the injection current. A Control: recording before moxonidine (MXD) perfusion. B MXD (I): recording starts $4 \mathrm{~min}$ after perfusion onset. The membrane potential became more depolarized, and an irregular firing with bursting periods was noted. The input resistance was increased. C MXD (II): recording starts $24 \mathrm{~min}$ after perfusion onset. The membrane potential was now notably hyperpolarized, and the firing rate was decreased. The input resistance remained increased. D Washout: recording starts $16 \mathrm{~min}$ after washout of moxonidine. The membrane potential had recovered to control levels, and the firing rate was increased, but the spike amplitude was notably reduced. erties similar to sympathetic premotor neurons in vivo [1]. This inhibitory effect was preceded by a transient depolarizing effect accompanied by an increase in firing rate. On the other hand, moxonidine at concentrations of $2 \mu M$ only produced a transient depolarizing effect without any further changes in membrane potential and electrophysiological properties on RVLM neurons with similar electrophysiological characteristics to those tested with moxonidine at a higher concentration.

In the in vitro slice preparation, the RVLM contains two different types of spontaneously active neurons: a first group shows a very regular firing pattern, while on the contrary, a second group has an irregular pattern of discharge $[4,6,25]$. These neuronal types could be related to premotor sympathetic neurons characterized in vivo.
In the present study we tested the inhibitory effect of moxonidine on both regularly and irregularly firing neurons. Therefore, it is possible to speculate that moxonidine injected in vivo could produce sympathoinhibitory and hypotensive effects, at least in part by inhibiting those sympathoexcitatory neurons in the RVLM. However, it is important to note the limitations of the in vitro slice preparations to characterize premotor sympathetic neurons, so it is difficult to determine the real number of premotor sympathetic neurons recorded in this study.

The present results still do not resolve the question of what type of receptor mediates this inhibitory response. As we mentioned, both $\alpha_{2}$-adrenergic and imidazoline type-1 receptors are postulated as the targets of the sympathoinhibitory effect of drugs like moxonidine [16]. 
Neuroanatomical and pharmacological studies have demonstrated that $\alpha_{2}$-adrenergic and $\beta$-adrenergic receptors are present in high density in neurons in the RVLM $[27,28]$. These receptors are functional because, first, local application of different $\alpha$ - and $\beta$-adrenergic agonists into the RVLM produced significant changes in arterial blood pressure, heart rate and sympathetic nerve activity $[8,12]$. The results of those investigations suggested that catecholamines, in particular adrenaline and noradrenaline, could play a role as neurotransmitters of neurons involved in cardiovascular sympathetic regulation in the RVLM.

In addition, the RVLM is also endowed with imidazoline type-1 receptors, which are proposed as being responsible for mediating the central hypotensive effect of moxonidine [29]. However, this hypothesis is not supported by the experiments reported by Hayar and Guyenet [30] showing that: (1) moxonidine, at concentrations similar to those used in the present study, produced a consistent inhibitory effect on different types of RVLM neurons recorded in an in vitro slice preparation, and this effect is due in part to postsynaptic hyperpolarization; (2) the inhibitory effects of moxonidine were substantially blocked by the selective antagonist of $\alpha_{2}$-adrenergic receptors SKF 86466, while on the other hand, the imidazoline type-1 antagonist AGN 192403 was ineffective in changing neuronal activity, and (3) the inhibitory effects of moxonidine characterized at pre- and postsynaptic levels are similar to those generated by norepinephrine and other $\alpha_{2}$-adrenergic agonists on putative presympathetic RVLM neurons. Similar results were reported by Szabo et al. [31] in experiments performed on the rat locus coeruleus neurons in vitro. Further support for the idea that the central sympathoinhibitory effect of drugs like clonidine (imidazoline derivative) is mediated by stimulation of $\alpha_{2}$ adrenergic receptors is provided by gene substitution experiments in the mouse. The replacement of only one amino acid of the $\alpha_{2 \mathrm{~A}}$-adrenergic receptor subtype produced a strain of mice with a remarkable downregulation in expression of $\alpha_{2 \mathrm{~A}}$-adrenergic receptors [32, 33]. These mutated mice lacked the hypotensive response to systemic injections of clonidine and other $\alpha_{2}$-adrenergic agonists.

However, Tolentino-Silva et al. [29] have published contradictory results. They demonstrated that: (1) microinjections of moxonidine directly into the sympathoexcitatory area in the mouse RVLM elicited a reduction in blood pressure at concentrations substantially lower than that needed to produce hypotension by systemic administration; (2) imidazoline type-1 receptors are pres- ent in the mouse RVLM in higher densities than the rat, and those receptors are solely necessary to mediate the hypotensive responses to moxonidine, and (3) the hypotensive effects of moxonidine tested in transgenic mice deficient in $\alpha_{2 \mathrm{~A}}$-adrenergic receptors were blocked with the selective imidazoline type-1 receptor antagonist efaroxan.

The present results show that moxonidine reproduces some of the effects of tyramine on putative sympathetic RVLM neurons as demonstrated in a previous publication [34]. However, the shorter latency depolarizing effects of tyramine and moxonidine that in the first case have been ascribed to activation of $\beta$-adrenergic receptors in the RVLM [14] could hardly be attributed to moxonidine. Indeed, there is no evidence that moxonidine is a $\beta$-adrenergic agonist. However, it is still possible to infer that the transient excitatory effect of moxonidine could have been mediated by the evoked release of endogenous catechols from terminals synapsing on the recorded neuron.

Concerning the ensuing hyperpolarizing effect, the question remains whether moxonidine and the endogenous catecholaminergic transmitter released by tyramine act on the same population of $\alpha_{2}$-adrenergic receptors. The current results demonstrate some similarities in the mode of action of both tyramine and moxonidine. However, it is still premature to advance any conclusion on this matter.

In conclusion, these results show that moxonidine $(10 \mu M)$ exerts a hyperpolarizing inhibitory effect on putative sympathetic neurons in the RVLM recorded in an in vitro slice preparation, and using a conventional intracellular recording technique. These results are in agreement with previous studies performed in brain stem slices of neonatal rats [30]. Nevertheless, in that study the authors used either an extracellular recording technique or a whole cell recording technique to study putative premotor sympathetic neurons which were identified mainly as retrogradely labeled RVLM bulbospinal neurons [30]. In our present study putative premotor sympathetic neurons were identified by their electrophysiological characteristics, as described in previous publications $[13,25]$.

\section{Acknowledgements}

This work was supported by a grant from the National Institutes of Health, Heart, Lung, and Blood Institute (HL-56733).

Moxonidine was generously supplied by Dr. Paul Ernsberger. 


\section{References}

1 Granata AR, Kitai ST: Intracellular analysis in vivo of different barosensitive bulbospinal neurons in the rat rostral ventrolateral medulla. $\mathbf{J}$ Neurosci 1992;12:1-20.

2 Zagon A, Spyer KM: Stimulation of aortic nerve evokes three different response patterns in neurons of rostral VLM of the rat. Am J Physiol 1996;271:R1720-R1728.

3 Huang WX, Yu Q, Cohen MI: Fast (3 Hz and $10 \mathrm{~Hz}$ ) and slow (respiratory) rhythms in cervical sympathetic nerve and units discharges of the cat. J Physiol (Lond) 2000;523:459-477.

4 Kangrga IM, Loewy AD: Whole-cell recordings from visualized $\mathrm{C} 1$ adrenergic bulbospinal neurons: Ionic mechanisms underlying vasomotor tone. Brain Res 1995;670:215-232.

5 Oshima N, Kumagai H, Kawai A, Sakata MK, Matsuura T, Saruta T: Three types of putative presympathetic neurons in the rostral ventrolateral medulla studied with rat brainstem-spinal cord preparation. Auton Neurosci 2000;84 40-49.

6 Lewis DI, Coote JH: The actions of 5-hydroxytryptamine on the membrane of putative sympatho-excitatory neurones in the rostral ventrolateral medulla of the adult rat in vitro. Brain Res 1993;609:103-109.

7 Kobinger W: Central $\alpha$-adrenergic systems as target for hypotensive drugs. Rev Physiol Biochem Pharmacol 1978;81:39-100.

8 Granata AR, Numao Y, Kumada M, Reis DJ: A1 noradrenergic neurons tonically inhibit sympathoexcitatory neurons of $\mathrm{C} 1$ area in rat brain stem. Brain Res 1986;377:127-146.

9 Ernsberger P, Meeley MP, Mann JJ, Reis DJ: Clonidine binds to imidazoline binding sites as well as $\alpha 2$-adrenoceptors in the ventrolateral medulla. Eur J Pharmacol 1987;134:1-13.

10 Ziegler D, Haxhiu MA, Kaan EC, Papp JP, Ernsberger P: Pharmacology of moxonidine an $\mathrm{I}_{1}$ imidazoline agonist. J Cardiovasc Pharmacol 1996;27(suppl 3):S26-S37.

11 Granata AR, Reis DJ: Hypotension and bradycardia elicited by histamine into the $\mathrm{C} 1$ area of the rostral ventrolateral medulla. Eur J Pharmacol 1987;136:157-162.

12 Privitera PJ, Granata AR, Underwood M Gaffney TE, Reis DJ: C1 area of the rostral ventrolateral medulla as a site for the central hypotensive action of propranolol. J Pharmacol Exp Therap 1988;246:529-533.
13 Granata AR, Cohen MI: Rhythmic properties of neurons in the rostral ventrolateral medulla of the rat in vitro: Effects of clonidine. J Neurophysiol 2002;88:2262-2279.

14 Sun MK, Guyenet PG: Excitation of rostral medullary pacemaker neurons with putative sympathoexcitatory function by cyclic AMP and $\beta$-adrenoceptor agonists 'in vitro'. Brain Res 1990;511:30-40.

15 Hayar A, Feltz P, Piguet P: Adrenergic responses in silent and putative inhibitory pacemaker-like neurons of the rat rostral ventrolateral medulla in vitro. Neuroscience 1997;77: 199-217.

16 Reis DJ: Neurons and receptors in the rostroventrolateral medulla mediating the antihypertensive actions of drugs acting at imidazoline receptors. J Cardiovasc Pharmacol 1996;27: S11-S18.

17 Clement ME, McCall RB: Effects of clonidine on sympathoexcitatory neurons in the rostral ventrolateral medulla. Brain Res 1991;550: 353-357.

18 Schreihofer AM, Guyenet PG: Role of presympathetic $\mathrm{C} 1$ neurons in the sympatholytic and hypotensive effects of clonidine in rats. Am J Physiol 2000;279:R1753-R1762.

19 Schmitt H, Schmitt H, Fenard S: Action of $\alpha$ adrenergic blocking drugs on the sympathetic centres and their interactions with the central sympatho-inhibitory effect of clonidine. Arzneimittelforschung 1973;23:40-45.

20 Prichard BN, Graham BR, Owens CW: Moxonidine: A new antiadrenergic antihypertensive agent. J Hypertens 1999;17(suppl 3):S41S54.

21 Van Zwieten PA: Centrally acting antihypertensive drugs: Present and future. Clin Exp Hypertens 1999;21:859-873.

22 Ernsberger P, Giuliano R, Willette RN, Reis DJ: Role of imidazole receptors in the vasodepressor response to clonidine analogs in the rostral ventrolateral medulla. J Pharmacol Exp Ther 1990;253:408-418.

23 Ernsberger P, Haxhiu MA: The $\mathrm{I}_{1}$-imidazolinebinding site is a functional receptor mediating vasodepression via the ventral medulla. Am J Physiol 1997;273:R1572-R1579.
24 Armah BI, Hoffereber E, Stenzel W: General pharmacology of the novel centrally acting antihypertensive agent moxonidine. Drug Res 1988;38:1426-1434.

25 Granata AR: Effects of $\gamma$-aminobutyric acid on putative sympatho-excitatory neurons in the rat rostral ventrolateral medulla in vitro. Intracellular study. Neurosci Lett 2001;300:49-53.

26 Paxinos G, Watson C: The Rat Brain in Stereotaxic Coordinates, ed 2. New York, Academic Press, 1986.

27 Unnerstall JR, Kopajtic TA, Kuhar MJ: Distribution of $\alpha 2$ agonist binding sites in the rat and human central nervous system: Analysis of some functional, anatomical correlates of the pharmacologic effects of clonidine and related adrenergic agents. Brain Res 1984;319:69101.

28 Alexander RW, Davis JN, Lefkowitz RJ: Direct identification and characterization of $\beta$ adrenergic receptors in rat brain. Nature (Lond) 1975;258:437-440.

29 Tolentino-Silva FP, Haxhiu MA, Waldbaum S Dreshaj IA, Ernsberger P: $\alpha 2$-Adrenergic receptors are not required for central anti-hypertensive action of moxonidine in mice. Brain Res 2002;86:26-35.

30 Hayar A, Guyenet PG: Prototypical imidazoline-1 receptor ligand moxonidine activates alpha2-adrenoceptors in bulbospinal neurons of the RVL. J Neurophysiol 2000;83:766-776.

31 Szabo B, Frohlich R, Illes P: No evidence for functional imidazoline receptors on locus coeruleus neurons. Naunyn Schmiedebergs Arch Pharmacol 1996;353:557-563.

32 Link RE, Desai K, Hein L, Stevens ME, Chruscinski A, Bernstein D, Barsh GS, Kobilka BK Cardiovascular regulation in mice lacking alpha2-adrenergic receptor subtypes b and c. Science 1996;273:803-805.

33 MacMillan LB, Hein L, Smith MS, Piascik MT, Limbird LE: Central hypotensive effects of the $\alpha 2 \mathrm{a}$-adrenergic receptor subtype. Science 1996;273:801-803.

34 Granata AR: Modulatory inputs on sympathetic neurons in the rostral ventrolateral medulla in the rat. Cell Mol Neurosci 2003;23:665680 . 